Email:jeffeygeorge@gmail.com

\section{References}

1. Herbert Z, Klienmen, Danville. Lingual varicosities. Oral Surg. 1974;23:546-8.

2. Ettinger RL, Manderson RD. A clinical study of sublingual varices. Oral Surg Oral Med Oral Pathol. 1974;38:540-5.

3. Jassar P, Jaramillo M, Nunez DA. Base of tongue varices associated with portal hypertension. Postgrad Med J. 2000;76:576-7.

4. Burket LW. Oral medicine. 4th ed. Philadelphia: JB Lippincott;1961.p.146.

\title{
Diagnosis of an early stage IPSID using Syndecan 1
}

\section{Introduction}

IPSID, traditionally termed Mediterranean lymphoma or Alpha Heavy Chain Disease, is a B cell neoplasm that arises in small intestinal mucosa-associated lymphoid tissue (MALT). It is characterized by the production of an unusual IgA heavy chain protein, called á heavy chain, which is secreted by plasma cells and is detectable in various body fluids. Patients may present in the second and third decades of life with chronic diarrhea, malabsorption, weight loss and abdominal pain. Clubbing of the fingers and nutritional deficiencies are characteristic, and palpable abdominal masses may be present. ${ }^{1,2}$ The most frequently affected sites are the duodenum and upper jejunum, but the pathology is diffuse with a mucosal cellular infiltrate involving large segments of the intestine and sometimes the entire length.

\section{Case report}

A 47-year-old male presented with a one week history of upper abdominal pain, vomiting and fever. He had lost 6 kilograms of weight over the previous one month. He did not have any comorbid illnesses. Neither did he smoke nor did he consume alcohol. Physical examination revealed that he was febrile, had tachycardia and clubbing. Abdominal examination revealed epigastric tenderness. Haemoglobin was $10.5 \mathrm{gm} \%$ and serum albumin was $3 \mathrm{gm} \%$. An erect abdominal X-ray was normal. Contrast enhanced CT scan of the abdomen was also normal. In view of the persistent symptoms an upper GI enteroscopy was performed, which revealed multiple ulcers in the proximal jejunum with mucosal edema. Biopsies from the ulcers showed a cellular mucosal infiltrate with destruction of the crypts and a reduction in crypt density, villi were short and broad (Figure 1). Immunohistochemistry showed cells which were LCA (Leukocyte common antigen) positive, CD3 (T cell marker) negative, CD20 (B cell marker) focally positive, IHC for kappa and lambda light chains was negative, Ki 67 showed low expression, and Syndecan 1 (plasma cell marker) was positive (Figure 2). Based on these findings we made a diagnosis of early stage IPSID. Serum alpha heavy chain levels were not

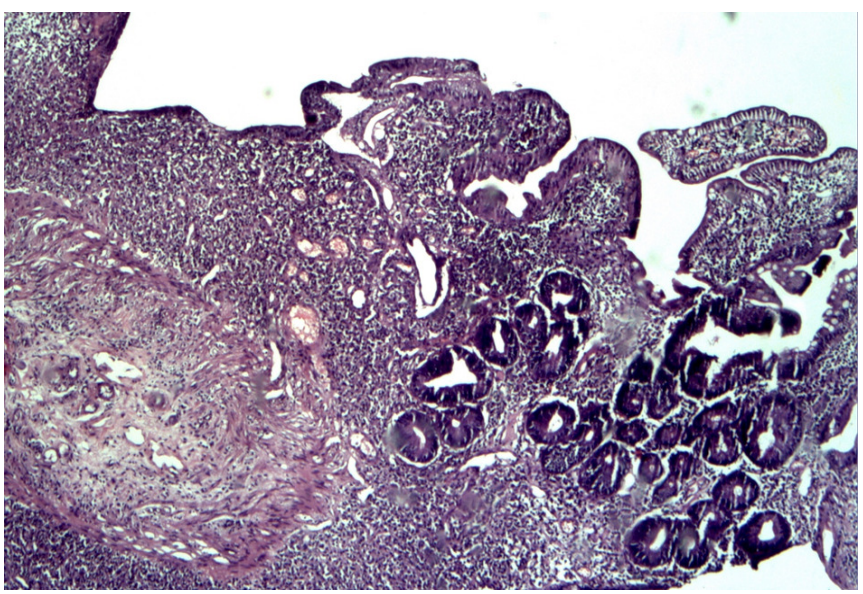

Figure 1: Photomicrograph showing a dense mucosal lymphocytic infiltrate with significant crypt loss and villous blunting (hematoxylin and eosin, 200X)

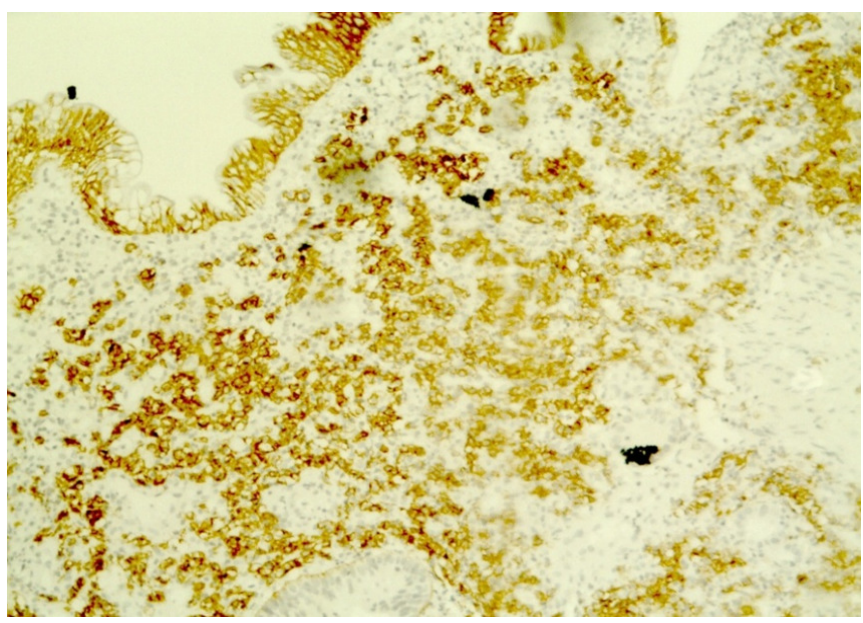

Figure 2: Photomicrograph showing the mucosal infiltrate staining positively for Syndecan-1 (CD138) immunohistochemistry (avidin biotin technique, 200X) 
measured. He was started on oral tetracycline and has been on follow-up for more than six months and is asymptomatic.

\section{Discussion}

IPSID accounts for $1.2 \%$ of all GI lymphomas in India ${ }^{3}$ and $2 \%$ of malabsorption syndrome in adults. ${ }^{4}$

The main pathologic feature is the presence of dense mucosal "centrocyte-like" infiltrates along with many plasma cells, involving long segments of the small bowel mucosa predominantly the proximal parts. The overlying epithelial cells are usually intact, the crypts are sparse, and the villi are short and broad. In the late stages, the villi are further broadened and may become completely effaced, crypts are fewer, and the immunoproliferation extends deeper. Over time the process evolves into overt lymphoma. Progression to higher grade large-cell lymphoplasmacytic and immunoblastic lymphoma is characterized by increased plasmacytic atypia with the formation of aggregates and later sheets of dystrophic plasma cells and immunoblasts invading into the submucosa and the muscularis propria. ${ }^{5}$ Vaiphei et al evaluated various immunohistochemical markers for the diagnosis and prognosis of IPSID. They highlighted the utility of Syndecan 1 for the identification of early stage IPSID. ${ }^{6}$

PRADEEP KAKKADASAM RAMASWAMI ${ }^{1}$ HARSHAD VINAY JOSHI ${ }^{1}$ RONY THOMAS ${ }^{1}$ RENU THOMAS ${ }^{2}$ CHARLES PANACKEL ${ }^{1}$ SUNIL K MATHAI ${ }^{1}$

Correspondence: Dr. Pradeep Kakkadasam Ramaswami Departments of Gastroenterologyl and Pathology, ${ }^{2}$ Medical Trust Hospital, Ernakulam, Kerala, India Email:drkrpradeep@gmail.com

\section{References}

1. Salem PA, Estephan FF. Immunoproliferative small intestinal disease: current concepts. Cancer J. 2005;11:374-82.

2. Lecuit M, Abachin E, Martin A, Poyart C, Pochart P, Suarez F, et al. Immunoproliferative small intestinal disease associated with Campylobacter jejuni. N Engl J Med. 2004;350:239-48.

3. Arora N, Manipadam MT, Pulimood A, Ramakrishna BS, Chacko A, Kurian SS, et al. Gastrointestinal lymphomas: pattern of distribution and histological subtypes: 10 years experience in a tertiary centre in South India. Indian J Pathol Microbiol. 2011;54:712-9.

4. Ghoshal UC, Mehrotra M, Kumar S, Ghoshal U, Krishnani N,
Misra A, et al. Spectrum of malabsorption syndrome among adults $\&$ factors differentiating celiac disease \& tropical malabsorption. Indian J Med Res. 2012;136:451-9.

5. Al-Saleem T, Al-Mondhiry H. Immunoproliferative small intestinal disease (IPSID): a model for mature B-cell neoplasms. Blood. 2005;105:2274-80.

6. Vaiphei K, Kumari N, Sinha SK, Dutta U, Nagi B, Joshi K, et al. Roles of syndecan-1, bcl6 and p53 in diagnosis and prognostication of immunoproliferative small intestinal disease. World J Gastroenterol. 2006;12:3602-8.

\section{A rare case of multiple inflammatory fibroid polypsin a young woman with family history of inflammatory fibroid polyps}

\section{Introduction}

Vanek $^{1}$ was the first to describe the inflammatory fibroid polyp (IFP). These polyps are rare, usuallysolitary,benign lesions, arisingfrom the intestinal submucosa and display a marked eosinophilic reaction. ${ }^{2}$ They have a slight male preponderance and are commonly seen in patients after the sixth decade of life. ${ }^{3}$ The stomach is the commonest site of origin, followed by the small bowel, colon and duodenum. ${ }^{4}$ Surgical resection is generally curative though recurrences have been reported if inadequate excision is done. ${ }^{5}$ Multiple inflammatory fibroid polyps requiring repeated laparotomies have been reported withinaffected families, up to over three successive generations. ${ }^{6}$ Only one other case of multiple polyps has been recorded, where the patient had one polyp each in the duodenum and jejunum. ${ }^{7}$ Most other case reports document only solitary IFPs, including solitary giant IFPs. ${ }^{8}$ Recurrence of multiple polyps has not been encountered up to now. We report a rare case of a young female patient who underwent three laparotomies for recurrent intestinal obstruction due to multiple IFPs.

\section{Case report}

A 30-year-old female patient first presented in 2002 with features 